\title{
LA PRODUCCIÓN DE UN ESPACIO COOPERATIVO
}

\author{
Samuel Ortiz Pérez \\ José Daniel Gómez López \\ Departamento de Geografía Humana. Universidad de Alicante \\ samuel.ortiz@ua.es, jd.gomez@ua.es
}

\section{RESUMEN}

El espacio, producido histórica y socialmente a partir de la acción y organización del proceso de trabajo, se reproduce en esencia condicionado por el modo de producción capitalista, su lógica de acumulación y su vocación geográficamente expansiva. La racionalidad espacial del capital se impone a través de la materialización de territorios para la acumulación y de territorios empobrecidos, una integración dialéctica del mismo proceso de producción espacial. No obstante, el trabajo cooperativo se presenta como un factor geográfico de primera magnitud para la transformación del espacio y de la sociedad.

Palabras clave: espacio geográfico, dialéctica, dinámicas territoriales, trabajo cooperativo, transformación.

\section{ABSTRACT}

The geographical space, which has been historically and socially produced by the action and organization of the work process, is essentially reproduced under the condition of the capitalistic model, where the logic of accumulation and geographical expansive vocation are the best important point. The spatial rationality of capital imposes a relationship between the territories for the accumulation and the impoverished territories; a dialectic

Fecha de recepción: enero 2015.

Fecha de aceptación: octubre 2015.

1 Este artículo ha sido realizado gracias a una Beca de Personal Investigador de carácter pre-doctoral concedida por la Consellería d'Educació de la Generalitat Valenciana, resolución del 27 de marzo de 2009 (BFPI2009/180). 
integration in the same spatial production process. Therefore, cooperative work is presented as a geographical factor of prime importance in order to transform the space and the society.

Keywords: geographical space, dialectic, territorial dynamics, cooperative work, transformation.

\section{INTRODUCCIÓN}

La carencia de estudios geográficos sobre el sector cooperativo y de la influencia del trabajo cooperativo en la producción del espacio es motivo suficiente para abordar algunas reflexiones y propuestas metodológicas que pueden contribuir a la ampliación de esta línea de investigación. Para ello se pretende demostrar la existencia de un amplio campo de estudio para la ciencia geográfica estrechamente vinculado a las implicaciones territoriales y espaciales, sociales y naturales derivadas de la organización del trabajo cooperativo.

De esta manera, el espacio queda considerado como un producto histórico y social que se reproduce en la lógica de un modo de producción caracterizado, entre otras cosas, por la generación de desigualdades sociales y desequilibrios territoriales que, a su vez, se materializan en la producción completamente asimétrica del espacio geográfico. Según esta tesis, ampliamente demostrada por autores como Milton Santos (2008b), David Harvey (2007a), Henri Lefebvre (2000a) o Piotr Kropotkin (1978), entre otros, la Geografía está obligada a cuestionarse las estructuras de poder establecidas y a proponer respuestas críticas y científicas para la transformación de la realidad total, social y espacial. Las tradicionales y útiles cuestiones universales de la ciencia ¿Qué? ¿Quién? ¿Cuándo? ¿Cómo? ¿Por qué? y ¿Para qué? pueden interrelacionarse a través de un método dialéctico aplicado al espacio y a las relaciones sociales existentes entre sí.

El enfoque de este artículo incide no solamente en el qué, cuándo, quién y dónde se materializa un objeto o una acción en el territorio de forma aislada; sino, y fundamentalmente, en el cómo y el porqué; es decir, en trasladar esas mismas cuestiones a un contexto de relaciones sociales que posibilite una explicación pormenorizada y en detalle de su esencia, permitiendo de esta manera hallar una mejor comprensión de cada categoría de análisis (objeto, función, forma, estructura, evento, etc.), o de cualquier otro fenómeno, en su imbricación dialéctica con la totalidad.

En suma, se propone abordar una serie de problemáticas relacionadas con el espacio geográfico que desafía la sociedad humana en el siglo XXI, con la finalidad de poder aportar nuevos planteamientos, por un lado, para el entendimiento y explicación de aquellas dinámicas que conciernen al espacio geográfico producido en la actualidad, y, de otro, al estudio de aquellas soluciones espaciales (posibles) al respecto.

\section{LA DIALÉCTICA DEL ESPACIO}

La aplicación en Geografía de un método materialista y dialéctico plantea una concepción de la realidad como una totalidad, una totalidad dinámica, en continuo movimiento, en cambio permanente; una realidad total en un constante proceso de transformación. Es decir, 
"una totalidad que se totaliza sin cesar, en la que los hechos particulares no significan nada (...) si no son tomados por la totalización en curso" (Sartre, 2005: 33). Para obtener un conocimiento profundo de esa totalidad no se pretende, sin embargo, estudiar el todo por el todo. La totalidad a la que se refiere está compuesta de partes internamente relacionadas bajo una causalidad dialéctica entre sí y que, a su vez, se constituyen como una totalidad en sí misma dentro de una totalidad mayor.

La realidad total puede conocerse a través de las partes y para conocer las partes se ha de conocer también el todo. El geógrafo brasileño Milton Santos destaca a este respecto que las partes y el todo son verdades parciales, por lo que para llegar a la verdad total es necesario reconocer el movimiento conjunto del todo y de las partes a través del proceso de totalización (Santos, 2009a: 120). Las partes, que pueden ser una totalidad en sí misma y presentan una cierta autonomía ${ }^{2}$, representan sustancialmente a la totalidad en la que se integran.

Para poder estudiar la totalidad real se hace necesaria, por tanto, su fragmentación en partes, entendiendo este proceso como una necesidad analítica sin perder la noción de integridad entre las partes y el todo ${ }^{3}$. Al hablar de la totalidad se hace referencia a una totalidad social que, según la concepción marxista, se trata de la totalidad de la sociedad humana en su máxima expresión; una totalidad que está compuesta de partes o estructuras dialécticamente dependientes. De ahí, el espacio se concibe como parte y todo de una realidad social mayor, de una totalidad social. Bajo el razonamiento del materialismo dialéctico, el espacio, como parte y todo, es dinámico y cambiante. Luego, lo que interesa y es verdaderamente relevante es el estudio del movimiento del espacio, es decir, la dinámica espacial que envuelve "los sistemas de acciones y los sistemas de objetos" (Santos: 2009a). Es a partir del movimiento, del análisis del proceso de totalización, que incluye el proceso de transformación de las partes en relación con la totalidad, de donde se podrá obtener el conocimiento real del espacio. Al mismo tiempo, esta concepción conlleva a asumir la existencia del espacio como una realidad objetiva ${ }^{4}$, es decir, independiente de la conciencia de la sociedad y de la percepción de las personas.

El desafío científico se encuentra, precisamente, en la definición que se efectúe sobre esas totalidades parciales más específicas y de su relación con la realidad total. Ello obliga a establecer una serie de categorías analíticas que integran y estructuran la realidad social ${ }^{5}$. En consecuencia, la identificación de categorías analíticas tiene como origen aquellos elementos (objetos) y fenómenos (acciones) derivados de lo concreto y observados en la realidad, una rea-

2 En este sentido, la autonomía no equivale a que sean totalmente independientes o a que se encuentren aisladas de la totalidad. La absoluta independencia de las partes no es admitida por la lógica dialéctica.

3 Existe, en cambio, una tendencia extrema hacia la división de las ciencias, especialmente en el ámbito de las ciencias sociales, siendo compartimentadas y consideradas como disciplinas separadas, como áreas de conocimiento o especialización ajenas entre sí, cuando todas forman parte de una única realidad social. Esta tendencia a la fragmentación y la actitud empirista de la ciencia perjudica seriamente al desarrollo del conocimiento humano. En el método dialéctico, la división analítica no es un fin en sí misma, sino un medio necesario de análisis de las partes en el camino del conocimiento de la totalidad en movimiento. Por consiguiente, unidad y diversidad forman parte de la misma realidad total.

4 Siguiendo la acepción de Durkheim sobre la consideración de los "hechos" como "cosas", Milton Santos concluye que "el espacio es una cosa, que se impone tanto al individuo como a la sociedad considerada como un todo" (Santos, 2008a:161).

5 Se entiende aquí una estructuración no cerrada e independiente, sino dialéctica e interdependiente. 
lidad que queda establecida como aquella "síntesis de la diversidad total” procedente del materialismo histórico. Así, con el fin de evitar caer en un simple empirismo, y en la determinación de elementos duales aislados, que subvalora las relaciones entre sí y las dinámicas, es preciso hallar todos los elementos de la realidad (espacial) bajo su relación dialéctica entre las partes y el todo. A propósito del espacio como categoría analítica y objeto de estudio de la Geografía, Milton Santos destaca que "el espacio es, antes de nada, la especificación del todo social, un aspecto particular de la sociedad global, (...) cuyas acciones, relaciones, producción específica y realización concreta solamente pueden darse en el espacio" (Santos, 2009a: 120).

En base a una concepción materialista y dialéctica sobre la dinámica espacial sujeta a un continuo proceso de evolución, se asume el principio de lo posible (que no de lo probable) acerca del movimiento cambiante de la totalidad real. Un argumento que permite estudiar aquellos proyectos y propuestas alternativas y coexistentes, aunque no dominantes, dotados de profundas implicaciones espaciales y territoriales.

El espacio geográfico expresa, por tanto, unas determinadas relaciones sociales transcritas a un proceso de producción espacial asentadas en un continuo movimiento de transformación: la dialéctica del espacio. El espacio geográfico forma parte de la realidad total como un elemento inserto plenamente en el proceso de totalización. Así, la dinámica espacial quedaría vinculada íntimamente a la transformación de la naturaleza por parte de la sociedad, por lo que «hay siempre una primera naturaleza lista a ser transformada en una segunda, una depende de la otra, porque la naturaleza segunda no se realiza sin las condiciones de la naturaleza primera, y la naturaleza primera siempre está incompleta hasta que la segunda naturaleza se realice. Este es el principio de la dialéctica del espacio» (Santos, 2008c: 214).

Desde esta concepción filosófica de la realidad, el espacio geográfico no es un elemento neutral que existe independientemente de la organización de la sociedad, el espacio es fruto de un proceso productivo ejercido por la sociedad humana a través de su acción sobre la naturaleza. Para el filósofo francés Henri Lefebvre (2000b) el espacio es abordado como un producto, un producto eminentemente social, un "espacio social producido" sumido en su realidad dialéctica, es decir, «el espacio no puede concebirse como algo pasivo, vacío, o bien sin ningún otro sentido, como los "productos", que no sea para intercambiar, consumir, desaparecer. Como producto, por interacción o retroalimentación, el espacio interviene en la producción misma: la organización del trabajo productivo, el transporte, el flujo de materias primas y de la energía, y las redes de distribución de mercancías. A su vez productivo y productor, el espacio interviene en las relaciones de producción y en las fuerzas productivas (mejor o peor organizadas). Su concepto no puede, pues, quedar aislado o permanecer estático. Este se dialectiza: producto-productor, como soporte de las relaciones económicas y sociales» (Lefebvre, 2000b: prefacio XX-XXI).

Así, inicialmente, se pretende prevenir de presuntas ambigüedades e interpretaciones que pueden surgir a lo largo el presente análisis, como es la clara distinción entre el ser (la realidad actual, el espacio producido) y el querer ser (la propuesta de una alternativa socioespacial, de un nuevo espacio), vinculado este último a un nuevo proyecto político, socioeconómico y espacial por parte de los movimientos sociales del campo. Esta concepción dialéctica del espacio se concreta en el análisis de cuatro categorías específicas: (i) el espacio como una producción histórica y social; (ii) el espacio del trabajo y la producción; (iii) el espacio por y para la reproducción del capital, y (iv) el espacio de la ayuda mutua y del trabajo cooperativo. 


\section{II.1. El espacio geográfico como producción histórica y social}

El espacio como producto social es el resultado de un proceso histórico que lo dota de una existencia objetiva ${ }^{6}$, independientemente de cómo cada persona lo interprete, imponiéndose a la sociedad (Santos, 2008c: 161). De tal modo, el conocimiento de la realidad espacial no puede basarse en sensaciones o percepciones sujetas a la experiencia o a la apariencia. El espacio es, por tanto, un producto de la organización social que ha transformado su entorno natural a lo largo de la historia, y este sobreviene de la capacidad (técnica e intelectual) del ser humano de organizarse en sociedad y ha evolucionado según las interrelaciones de tipo dialéctico que se han dado en él y con él; en consecuencia, el espacio se convierte en la "realización de la historia, siendo pasado, presente y futuro al mismo tiempo". (Santos, 2009a: 156). El espacio geográfico entendido así, como un resultado activo de un proceso productivo de la organización de la sociedad humana a lo largo del tiempo, reafirmando por ende su carácter social, su reproducción social. Es decir, el espacio considerado como un producto social, a la vez que el ser humano se halla como creador y escultor del espacio.

En la línea argumental de Milton Santos, es preciso tratar el espacio como una instancia social más, como una categoría fundamental para cualquier tentativa de teorización social acerca de cualquier fenómeno ${ }^{7}$. Y cabe reivindicar el espacio como una instancia de la sociedad al mismo nivel que la instancia económica, la ideológica, la política-institucional, la cultural, en la que el espacio está incluido en otras instancias y también las otras instancias incluyen al espacio; así pues, "el espacio contiene y es contenido por las demás instancias" (Santos, 2008a: 12). Se entiende, asimismo, el espacio como un factor fundamental de la evolución social, en el que todas las instancias se interrelacionan, lo que implica una imbricación entre las mismas. Por consiguiente, el espacio queda reafirmado como una categoría explicativa central de la realidad social.

Esta relación dialéctica sobre la producción histórica del espacio obliga, por un lado, a rechazar la noción kantiana del espacio como un mero escenario donde se suceden los hechos sociales de la historia, como un elemento pasivo; y, por otro lado, a entender simultáneamente el espacio como una herencia y una posibilidad, hecho que lo convierte, al mismo tiempo, en resultado y condición de la reproducción social, en un factor significativo en la evolución de la sociedad. El espacio como posibilidad, en estado de movimiento cambiante, coincide con la afirmación del francés Paul Vieille cuando indicaba que "el espacio es una dimensión activa en el devenir de las sociedades" (en Santos, 2008c: 186) ${ }^{8}$.

De esta forma, se propone continuar con la disposición de abordar el conocimiento real del espacio no solo por las relaciones, sino por los procesos (Santos, 2008c: 84), superando así la percepción tradicional de las relaciones entre el ser humano y la naturaleza como una

6 Milton Santos aclara seguidamente que una cosa es la percepción individual del espacio y otra su objetividad. El espacio no es la síntesis de las percepciones individuales; el espacio es un objeto social como cualquier otro (Santos, 2008c: 161).

7 Santos denuncia un olvido generalizado, inclusive desde la tradición marxista, que ignora esta percepción, como se demuestra en los trabajos de Althusser, Plekhanov, E. Cohen o M. Harnecker (Santos, 2008c: 178-179).

8 Esta concepción del espacio como posibilidad, como devenir de una nueva sociedad, servirá de argumento transcendental para defender las alternativas propuestas de relación social sustentadas por la acción práctica de los movimientos sociales y de su proyecto socioespacial. Es en la "lucha de los contrarios" en lo que se fundamenta las leyes de la dialéctica caracterizada en las obras marxistas. 
relación dualista, empirista, como una simple relación de opuestos aislados. En síntesis, un estudio fundamentado en el análisis diacrónico y sincrónico del espacio en su dinámica histórica, como un producto social sujeto a un movimiento permanente y cambiante.

\section{II.2. El espacio del trabajo y de la técnica}

El espacio geográfico, como producto histórico y social, es resultado de una transformación continua de la naturaleza. Esta transformación de la naturaleza se realiza a través de un proceso de trabajo productivo por parte de los seres humanos y de la sociedad en su conjunto. Existe una interacción mutua entre naturaleza-sociedad y sociedad-naturaleza como elementos interdependientes que componen un todo social bajo las reglas de la dialéctica, es decir, se encuentran en constante movimiento debido a una lucha contradictoria inherente a su propia realidad totalizadora ${ }^{9}$.

El reconocimiento histórico de la práctica humana del trabajo como elemento transformador de la naturaleza provista por Karl Marx (1975c; 2010) permite visualizar el paso de una naturaleza natural o naturaleza primera a una naturaleza social o segunda naturaleza, una naturaleza transformada. Esta segunda naturaleza es la que se considera como el espacio geográfico, una naturaleza social o socializada (Santos, 2008c: 203), construida a partir del trabajo de la sociedad y en sociedad, es decir, una naturaleza producida socialmente. De esta manera, esta naturaleza socializada (el espacio geográfico) será considerada como una (sub) totalidad en sí misma, una parte y un todo de la realidad social total, la cual se convierte en el objeto de estudio de la Geografía, y en aquello que constituye el conocimiento geográfico.

Una vez que el proceso de trabajo o de producción implica una organización, este se organiza espacialmente. Esta idea del espacio geográfico como un espacio del trabajo y de la producción también es argumentada por Ruy Moreira (1993), que considera el espacio como la materialización del proceso de trabajo, en el que la relación entre el ser humano y la naturaleza se basa en una relación de trabajo, debiendo analizarse en su expresión histórica concreta. En síntesis, sería afirmar que "el acto de producir es, al mismo tiempo, el acto de producir espacio, siendo actos indisociables" (Santos, 2008c: 203).

El espacio, pues, será el resultado material (e inmaterial) de la organización del proceso de trabajo de una sociedad a lo largo de la historia, que significa reconocer que el espacio humano es el resultado de una producción concreta, en cualquier periodo histórico, lo que Lefebvre (2000b) denomina la "historia del espacio". Y es a partir del acto de trabajar y de la historia del trabajo productivo como la sociedad se transforma a sí misma y al espacio, y mediante el cual el ser humano adquiere una mayor humanización (Gomes, 1991: 23). A partir de este proceso de humanización es donde el desarrollo de la técnica, el uso y perfeccionamiento de los instrumentos de trabajo y la organización técnica del trabajo productivo son considerados indispensables para entender la capacidad de transformación del espacio de la sociedad en su transcurso histórico, así «la promoción del hombre-animal a hombre social se da cuando el humano comienza a producir, es decir, a obtener de la naturaleza

9 Durante los años treinta del siglo XX, George Politzer, profesor de la Universidad Obrera de París, explicó detalladamente en qué consiste la concepción dialéctica de la realidad y cómo funcionan las leyes de la dialéctica: 1) El cambio y el movimiento; 2) la acción recíproca de los procesos; 3) la contradicción, y 4) la transformación de la cantidad en calidad (Politzer, 2002) 
los elementos indispensables para la reproducción de su vida, mediante el trabajo (...) $L a$ producción, pues, supone una intermediación entre el hombre y la naturaleza» (Santos, 2008c: 202).

Para estudiar las relaciones de trabajo, la organización de la producción y de los intercambios de bienes materiales de una sociedad a lo largo de la historia se aplica el término de "modo(s) de producción" como una categoría de análisis básica para entender el proceso de producción espacial. El modo de producción hace referencia a una totalidad social orgánica ${ }^{10}$, más allá de un simple concepto económico, y que engloba también la instancia políticainstitucional, ideológica y cultural dentro una realidad social total.

Cada modo de producción se materializa, a su vez, en el espacio y con el espacio. David Harvey problematiza este concepto de forma esclarecedora en Los límites del capitalismo y la teoría marxista (1990), distinguiendo las posibles variaciones de uno de los términos más usados en la teoría marxista de la historia, en la que ni siquiera el propio K. Marx, ni tampoco F. Engels, dieron una única definición concreta, tal vez por la diversidad de causalidades dialécticas (Harvey, 1990: 36-37). Una primera aproximación del término que ofrece el geógrafo británico es aquella que comprende "los métodos y técnicas que se usan en la producción de una determinada clase de valor de uso"; por ejemplo, el modo de producción agrario o textil. Una segunda aplicación indica que se trata de "la representación abstracta de un conjunto de relaciones definidas, donde se combinan las fuerzas productivas (capacidad de transformar la naturaleza) y las relaciones sociales (de clase) en el proceso de trabajo para definir el modo de producción característico", haciendo referencia a la técnica, la propiedad de medios de producción y el posicionamiento en el proceso de trabajo. Y en tercer lugar, el modo de producción se concibe como un concepto más holístico, global, refiriéndose a "toda la gama de relaciones de producción, intercambio, distribución, consumo, institucionales, jurídicas, administrativas, relacionadas con la organización política y aparato del Estado, ideología y formas de reproducción social", combinados de forma dialéctica en una totalidad social.

Teniendo en cuenta esta argumentación, en la mayor parte del artículo se hace mención propiamente a esta última definición, el modo de producción aplicado en su concepción más amplia. Sin embargo, tanto la primera como la segunda también están presentes en la misma a la hora de abordar la coexistencia de diferentes modos de producción, particularmente al abordar un diagnóstico pormenorizado del modo de vida campesino y a la organización productiva del sistema agroindustrial (agroalimentario). No cabe duda de que hay que recurrir a la primera y a la segunda definición para poder entender el significado de la tercera, donde el modo de producción queda entendido como condicionante de la vida en sociedad. Por tanto, el espacio puede considerarse como un producto del trabajo de los seres humanos resultado tanto de la sucesión histórica como de la convivencia de modos de producción existentes, tratándose a su vez de un factor activo en el devenir de las sociedades.

No obstante, el espacio aparece, en consecuencia, como resultado activo de un modo de producción dominante, de las relaciones sociales de producción y de unas técnicas concretas aplicadas al trabajo productivo; una idea de "medio geográfico" que, como asegura Santos,

10 Como bien indica Marta Harnecker, para diferenciarlo del concepto hegeliano de "totalidad social expresiva" (Harnecker, 2007: 154). 
es inseparable de la noción de técnica (Santos, 2009a: 234) ${ }^{11}$. En el proceso de producción social existe un uso consciente de los instrumentos de trabajo con unos objetivos establecidos y bajo una lógica determinada, que establece una cierta división de tareas, es decir, una necesidad de aplicar una división del trabajo, una división que es social y territorial. Esta división queda expresada mediante una función técnica y social, cuyas relaciones forman parte de una compleja realidad de relaciones de producción, constituyéndose asimismo en una dinámica espacial racional.

De este modo, la producción impone una forma de vida, una manera de reproducción social, una racionalidad espacial de organización del tiempo y del espacio mediante la organización de la técnica. La técnica se proyecta como una mediación entre el ser humano y su capacidad de transformar la naturaleza a lo largo del tiempo, es un indicador de la forma y la intensidad en las que ha sido modificado el espacio a lo largo de la historia, por lo que la técnica establece la unión entre el tiempo y el espacio; siendo que, a través de las técnicas el hombre, en el trabajo, realiza esa unión entre el espacio y el tiempo, es decir, las técnicas dan la posibilidad de empirizar el tiempo (Santos: 2009a: 54). Las técnicas han variado a lo largo del tiempo, y unas alteraciones de la función técnica y de los instrumentos de trabajo cambian las relaciones entre la sociedad y la naturaleza, se produce un cambio del uso social del tiempo y, por tanto, de la organización del espacio.

En este sentido, las nuevas tecnologías, especialmente las tecnologías de la información, la robótica y las comunicaciones, sirven de mediadoras entre el trabajo, la producción y el espacio producido. Una dinámica espacial altamente condicionada en la actualidad por la lógica del modo de producción capitalista que impone unas relaciones determinadas de trabajo, unas formas concretas de organización de la producción, y unas particulares relaciones sociales y técnicas de trabajo, todas ellas aptas y adaptadas a su lógica de reproducción y acumulación. Es decir, se está produciendo un espacio por y para el capital.

\section{III.3. El espacio producido por y para la reproducción del capital}

Para teorizar sobre el espacio geográfico es conveniente aludir a las implicaciones generales que derivan del capital como modo de producción; y más específicamente, del capital como proceso. Un proceso determinado por la circulación del capital y la lógica de la (re) acumulación de capital.

De esta manera, concierne caracterizar y detallar las dinámicas particulares que impone el capital a su espacio, un espacio configurado para y por su lógica de acumulación. En este sentido, el capital es (espacialmente) selectivo. El capital selecciona "sus territorios" para su acumulación y se localiza según unas preferencias determinadas, jerarquizando el espacio. De ahí emerge la esencia de la diversidad de territorios y de lugares existentes, cada uno con sus características singulares; los cuales todos ellos forman parte, sin embargo, de una misma dinámica espacial global -mayor-. La organización del espacio es altamente sensible a las exigencias del capital para su reproducción, escogiendo de esa manera aquellos territorios

11 Para Santos, las transformaciones naturales como la domesticación de las plantas y de los animales (agricultura y ganadería), a lo que podríamos añadir la propia agroecología, tienen su fundamento en la técnica. Para conocer de manera más pormenorizada la relación entre técnica y espacio que establece el propio Milton Santos, cabe consultar los capítulos 1 y 10 de su obra A natureza do espaço. 
óptimos donde localizarse. De modo que, la selección y fragmentación territorial se debe, en última instancia, a tales criterios de eficiencia económica y de rentabilidad del capital. Así, el propósito de acumular capital implica a su vez el imperativo de superar los obstáculos espaciales creados por el desarrollo del propio capitalismo ${ }^{12}$. Se halla aquí una de las principales contradicciones espaciales del modo de producción capitalista. En la superación de esta contradicción, subraya Harvey, "tanto la expansión geográfica como la concentración geográfica se consideran producto de la misma lucha por crear nuevas oportunidades de acumular capital" (Harvey, 2007: 264). De esta característica selectiva del capital deriva la existencia de territorios "centro" y territorios "periferia", obviamente no desde una referencia geográfica, sino desde la perspectiva de la acumulación de capital. Ello supone una acentuación en la jerarquización del espacio mediante la generación de nuevas centralidades para el capital. De esta lógica deriva igualmente la distinción entre territorios "empobrecidos" y territorios "enriquecidos", integrados ambos en la organización capitalista del espacio. Otra disyuntiva hace mención a los territorios imbricados de acumulación y territorios de empobrecimiento que estructuran el aparente "desorden" en el espacio seleccionado por el capital. Esta relación dialéctica entre la universalidad y particularidad de los fenómenos, la relación entre las partes y el todo, correspondería a la interrelación surgida hoy entre lo local y lo global ${ }^{13}$ que implica el momento actual de expansión capitalista hacia un espacio global.

Asimismo, el capital, en su forma de capital-dinero y capital-crédito, ha alcanzado un excepcional nivel de autonomía sin precedentes. El capital, en su forma de sistema de crédito (capital financiero) se convierte en un elemento fundamental en la producción del espacio mediante la especulación financiera y su particular sentido del valor. Como bien apuntaba hace más de un siglo Marx (2010b), y destaca igualmente Harvey (2007a), el sistema de crédito ha concedido la autonomía suficiente al dinero para emprender un nuevo ciclo de producción y de acumulación de capital bajo una economía especulativa ${ }^{14}$. Esta es una de las consecuencias surgidas de la necesidad de eliminar el espacio mediante el tiempo en el proceso productivo, un hito histórico conseguido a partir de la aparición de un sistema de crédito que permite una ampliación geográfica del mercado ${ }^{15}$ gracias a las nuevas tecnologías, con el fin de superar el espacio con el tiempo (Harvey, 2007b: 96) por medio de la velocidad de movimiento y de los intercambios, en un sentido amplio. Este es un hecho de cuya relevan-

12 A estos obstáculos Milton Santos los denomina "rugosidades"; mientras que Jean Paul Sartre se refiere a ellos como el "práctico-inerte".

13 Con la globalización del mercado mundial capitalista se ha difundido a su vez el término global-local, o lo que se ha venido en llamar "glocalización", que hace referencia a la concepción dialéctica de lo universal y lo particular de los fenómenos y de su interdependencia. Por tanto, lo que se percibe en un lugar (local) cristaliza una dinámica general mayor (global).

14 Se refiere a que el dinero parece hacer dinero sin pasar por el proceso de producción de mercancías ni de circulación real, provocando una disociación con los medios de producción y la elaboración de mercancías, separadas en el tiempo y en el espacio, aunque apropiándose también durante este proceso de una parte de la plusvalía generada. Este fenómeno llevaría a considerar el sistema de crédito y de capital financiero como un factor no visible y poco perceptible de las transformaciones del espacio a nivel global. Es decir, se trata de una economía especulativa con incidencia directa en el espacio geográfico.

15 En el libro Las crisis del capitalismo, escrito a mediados del siglo XIX, Marx explica más detenidamente el proceso de separación del tiempo y del espacio en el mercado capitalista, que se debe, entre otras razones, al proceso de expansión del capital en el que los intercambios ya no precisan coincidir ni en un mismo momento ni en un mismo lugar (Marx, 2010: 96). Véase también Harvey (2007a), Santos (2009a). 
cia espacial también advierte Milton Santos cuando afirma que la plusvalía, reconvertida en mundial por la generalización de la producción y unificada por intermedio del sistema bancario ${ }^{16}$, constituye el motor primero en el actual espacio geográfico del capital (Santos, 2008d: 47). Tal dinámica espacial basada en la tecnología y la velocidad ha transformado la lógica espacial del proceso productivo, haciendo más complejos los factores de localización industrial y fortaleciendo progresivamente el poder del capital financiero sobre el espacio geográfico de forma nada desdeñable. A través, sobre todo, del control de las tecnologías de la información se ha favorecido, sin duda, una extraordinaria libertad de movimientos a todos los niveles, pero que ha posibilitado de manera preferencial una libertad de circulación de capitales a nivel mundial, no ligadas apenas al trabajo productivo real.

También, el capital, debido a sus contradicciones internas, está abocado a la existencia de crisis estructurales provocadas en el seno de su propio modo de producción. La teoría marxista reivindica el carácter endémico de las crisis del capital (Luxemburg, 2009: 23), que reclama su actual vigencia y valor en la explicación de los fenómenos sociales. La superación de las contradicciones internas del capital provoca a su vez una "solución espacial" de la crisis (Harvey, 2007; Lenin, 1974). En la lógica de acumulación de capital, tanto la reproducción de las contradicciones internas del modo de producción capitalista, como los intentos de superación de las mismas, representan una racionalidad espacial específica, lo que conlleva la territorialización del empobrecimiento en el propio espacio del capital: situaciones de inseguridad alimentaria y desnutrición, hambre, intensificación de las migraciones, flexibilización laboral, el desempleo, la disminución de salarios, reducción del gasto social, la reorganización del sistema productivo y la deslocalización industrial, la violencia (urbana y rural), la depredación ambiental, procesos de concentración del proceso productivo (fusiones y absorciones), intensificación de los monopolios económicos, etcétera. Así pues, las crisis estructurales inherentes del capital conducen obligatoriamente a una reorganización de su espacio que favorezca prioritariamente la creación de nuevos territorios para su reproducción y lógica de acumulación, con todas sus consecuencias.

Luego el capital es un proceso creador de necesidades constantes y está supeditado a una práctica de consumo continuo. La creación de necesidades requiere a su vez una satisfacción universal de las mismas. Está dinámica queda ligada a la teoría del valor, es decir, a las transformaciones producidas entre el valor de uso y el valor de cambio (Marx, 1975a, 1975b, 2010a). En la fase post-fordista del modo de producción capitalista se destina una oferta de mercancías cada vez más especializada y diversificada de productos a mercados cada vez más competitivos, exigentes y alejados; acompañada, asimismo, de potentes campañas publicitarias responsables de "generar nuevas necesidades" y pautas de consumo de mercancías que convierten la práctica consumista en otro elemento productor de espacio. Y así, el espacio se convierte en una mercancía más, es decir, "se compran y se venden pedazos de espacio para la reproducción de la vida” (Carlos, 2007: 175).

El evidente predominio de las relaciones sociales de consumo inducidas por el modo de producción capitalista impone su racionalidad y su lógica en cualquier territorio del mundo, mediante la generalización del valor de cambio (comercio) frente al valor de uso (produc-

16 Se ha transformado el proceso productivo tradicional M-D-M por otro: D-M-D. El capital financiero se ha consolidado como una industria en la cual el dinero produce dinero. 
tivo), una mercantilización de absolutamente todos los aspectos de la vida, sometiendo al espacio a una valorización cada vez mayor por parte del capital, donde todo tiene un precio, todo se puede comprar y vender, efectivamente todo. En este sentido, el acceso al crédito para el consumo y la inversión, es decir, la dependencia social sujeta a quien tenga acceso al crédito y posea una mayor liquidez económica implicará una nueva selección espacial. De esta manera el capital somete bajo su racionalidad a toda forma de organización social que se encuentra en el interior de sus dominios (Moraes y Messias, 1985: 64), perturbando así cualquier tipo de relación social y modo de vida ${ }^{17}$. Podría incluirse el propio papel del Estado que, mediante el ejercicio de sus políticas públicas y de la aplicación de su poder legislativo, crea las condiciones legales espaciales adaptadas a la racionalidad consumista del capital, lo que se ve reflejado en planes urbanísticos, en la planificación de las infraestructuras, en la distribución de los impuestos, en la programación de las políticas públicas y en otras numerosas concesiones (legislativas y económicas) favorables a la circulación del capital.

De la misma forma, el capital es un proceso "privatizador": privatizador de espacios, de conocimientos y de beneficios. Es decir, el derecho a la propiedad privada es uno de los dogmas fundamentales para la acumulación (privada) del capital, y no hay acumulación sin la privatización de la plusvalía, de los beneficios, de los medios de producción, y tampoco sin la apropiación del territorio. Así, por ejemplo, la propiedad privada del suelo es la mayor expresión del proceso de separación del ser humano y su espacio (Moraes y Messias, 1985: 88). De la misma forma, el saber, en especial el saber científico, la investigación, el conocimiento y la información en general están sujetos a un proceso de privatización continuo al servicio del capital ${ }^{18}$. Ello conlleva a considerar la educación, la formación y la información como elementos de carácter geoestratégico, fundamental para entender la dinámica de producción y transformación del espacio.

Además, el capital tiende esencialmente a la concentración y, por ende, se dispone como un factor urbanizador de primer orden. La lógica del capital impone la concentración de los medios de producción (tierra, máquinas, fábricas, tecnología, información, etcétera); la concentración de la fuerza de trabajo y de la mano de obra; la concentración del potencial de consumo y de los servicios; y, de la misma forma, el proceso de concentración se traduce en la consolidación de monopolios productivos (preferentemente en la esfera de la comercialización y distribución de mercancías), y también financieros, mediante procesos de fusión, absorción, compras, transferencias, etcétera, fruto de la competición intercapitalista por la supervivencia y la eliminación de competidores. Una dinámica que queda cristalizada en la concentración de la población en ciudades y áreas metropolitanas (macrocefalias urbanas). Esta dinámica de concentración y su vocación claramente urbana implica una asociación directa con aquellos fenómenos de éxodo rural y de (semi)proletarización en el medio rural,

17 Aún admitiendo un sometimiento de la racionalidad capitalista a todos los ámbitos de la vida y en la producción del espacio, no se entiende aquí como un domino absoluto y total. Ello permite afirmar la coexistencia de otros modos de producción o modelos de organización del espacio pero que, sin duda, están condicionados, a veces subordinados, por la mercantilización impuesta por la lógica de acumulación capitalista. Será importante esta noción de coexistencia sobre todo en la discusión acerca de la organización económica campesina.

18 Como ejemplo se encuentra el reciente proceso de construcción del Espacio Europeo de Educación Superior (EEES) y el nuevo rol de la universidad configurado por el propio Banco Mundial décadas atrás. 
que indican serias desigualdades entre la vida en el campo y en la ciudad ${ }^{19}$. Empero, la sobreconcentración y el urbanismo masificado generan a su vez sus propias contradicciones y desequilibrios, provocando procesos inversos de desconcentración y ocupación de nuevos lugares. Precisamente este fenómeno es inherente al movimiento dialéctico de concentración y expansión, de concentración y fragmentación territorial.

Dialécticamente vinculada con la característica anterior, el capital es expansionista y depredador de la naturaleza. Es una de las principales consecuencias surgidas de sus crisis estructurales. La presunta "solución espacial" de las crisis del capital a las que alude Harvey (2007a), haciendo referencia sobre todo a los pronósticos de Marx y Lenin, queda representada por la división internacional (territorial) del trabajo y del proceso de producción, en la búsqueda de nuevos mercados, $y$, en definitiva, en la procura de nuevas oportunidades de acumulación de capital, donde quiera que sea viable, configurando así el denominado "mercado mundial". Para Milton Santos, cuando la división del trabajo y la cooperación perversa por ella ocasionada se extienden a escala del planeta, el mundo se convierte en un espacio global del capital (Santos, 2009b: 23). Esta perversión conlleva básicamente, con todas sus repercusiones, la explotación de las personas, el expolio de los territorios y la depredación de todos sus bienes naturales bajo criterios de crecimiento, desarrollo, rentabilidad y eficiencia económica; es decir, bajo la racionalidad espacial del capital y su lógica de reproducción, directamente interrelacionada con la conversión de todo, absolutamente todo, en mercancía o valor de cambio.

No obstante, a pesar de ello, y para conservar su propia reproducción, el capital necesita ser creativo, estar en movimiento, en constante proceso de evolución, reinventándose. El avance de la técnica y de las tecnologías, de la investigación e innovación, está sujeto sin embargo, a poderosas inversiones multimillonarias, privadas y también públicas, con la esencial finalidad de conseguir nuevas estrategias de acumulación. En la intencionalidad de la técnica, de los objetos y estructuras creadas, es donde yace una parte del análisis dialéctico del espacio, pero no de forma neutral o aislada del contexto donde se instaura. De una forma implícita, se incurre en el debate de cómo, dónde y para qué se utiliza la técnica y los avances de la tecnología en el devenir de la humanidad. Una cuestión de indudable reconocimiento histórico y social, aunque se encuentra frecuentemente subordinada a la racionalidad espacial del capital. En materia agroalimentaria, esta intencionalidad interpela a las nuevas pautas de producción, distribución y consumo implantadas durante el último medio siglo.

Con especial relevancia, se puede afirmar que el capital también coopera. La cooperación en el modo de producción capitalista continúa siendo una realidad patente. Cuando Marx habla de "cooperación simple y cooperación compleja", o de "socialización de los medios de producción”, lo hace para referirse a las relaciones sociales y relaciones técnicas de producción sometidas a la lógica del modo de producción capitalista, insertas en el modo de producción, sin alterar la lógica de status de explotación entre personas, entre clases sociales.

19 No pocas veces se ha exclamado en diferentes ámbitos sociales el desprecio por la vida en el campo, el modo de vida rural o campesino, considerando esta una forma de vida "inferior" y "no desarrollada" frente al discurso moderno de lo urbano y el desarrollo medido en índices de urbanización y de crecimiento. Este discurso, asumido profundamente incluso por las familias campesinas y la población rural, contribuye a la lógica urbanizadora del capital, donde la ciudad se presenta como símbolo del progreso y de mejora de la sociedad. 
Con ello, Marx apunta a una cooperación más bien técnica durante el proceso de trabajo, diferenciando unas (clase burguesa) que son propietarias del capital y de los medios de producción frente aquellas otras que poseen (y venden) esencialmente su fuerza de trabajo (clase trabajadora). Además, ante los intereses privados del capital, el Estado-Nación, surgido en la época moderna, representa un fiel aliado, un aliado de clase (Lenin, 1976). La existencia de una cooperación o intercooperación en el seno de la clase burguesa (intercapitalista), y entre ella y los estados, no es nada despreciable. Los Estados y las instituciones contemporáneas ${ }^{20}$ ponen a su disposición la ley o leyes, la fuerza militar y la seguridad, la financiación económica, la información, la política y también su territorio. En este sentido, tal y como subraya el investigador de economía crítica Josep Manuel Busqueta, la Unión Europea sería "un espacio geográfico legal adecuado para la circulación y acumulación de capital, un espacio de competitividad extrema construido desde la legalidad"21. La creación y consolidación de alianzas y monopolios en forma de trust, holding o cartel económicos y territoriales, representan hasta el día de hoy el mayor grado de intercooperación y de redistribución de intereses meramente capitalistas y privados. El mejor ejemplo de "territorios privados", espacios eminentemente necesarios para la circulación y acumulación de capital, sería, obviamente, la existencia de los paraísos fiscales. Sin esta destreza cooperativa sería difícil comprender la fortaleza del capitalismo en la sociedad actual.

Sobre la práctica del capital, Immanuel Wallerstein apunta que «lejos de ser un sistema "natural", como algunos apologistas han tratado de mantener, el capitalismo histórico es un sistema patentemente absurdo. Se acumula capital a fin de acumular más capital. Los capitalistas son como ratones en una rueda que corren cada vez más deprisa a fin de correr aún más deprisa. En el proceso, sin duda, algunas personas viven bien y otras en la miseria; y ¿cómo de bien, y durante cuánto tiempo, viven los que viven bien?» (Wallerstein, 1988: 30-31).

Desde una concepción dialéctica sobre la lógica de funcionamiento del modo de producción capitalista, el proceso de "acumular por acumular", "producir por producir" representa el hilo conductor de su actividad económica, para la apropiación continua de una plusvalía relativa. Una elemental contradicción generada entre el capital y el trabajo es el proceso de sobreacumulación y sobreproducción capitalista, es decir, la producción de excedentes de capital que no pueden ser absorbidos y que se insertan en una dinámica de devaluación y de crisis. Las crisis, como se señalaba anteriormente, son realidades estructurales y endémicas del propio sistema capitalista, que intentan mitigar su vocación infinita por la sobreproducción y sobreacumulación.

La identificación de estas dinámicas predominantes revela una condicionalidad del modo de producción capitalista en la producción del espacio, determinada, entre otras cosas, por una manera concreta de organizar el proceso de trabajo. Lo que supone una reorganización y reproducción territorial continua, en un espacio producido por y para la lógica del capital, atendiendo a su específica razón de ser y de existir: la lógica de acumulación.

20 Estado e instituciones burguesas, gobernados por la clase burguesa, para velar por sus intereses de clase.

21 Conferencia impartida en la sede de la Universidad de Alicante con el título "El procés de construcció de la Unió Europea”, el 31 de mayo de 2011, organizada por el Movimiento de Resistencia Global de Alicante -MRG-. 


\section{II.4. El espacio de la ayuda mutua y del trabajo cooperativo}

La cooperación desarrollada en el proceso de trabajo ${ }^{22}$, entendida aquí como la acción social de la ayuda mutua y solidaridad, ha sido históricamente una práctica fundamental en las relaciones entre seres humanos, un hecho indispensable de la vida común en sociedad. Las interacciones sociales y territoriales generadas por esta cooperación obligan a introducirla como factor a la hora de abordar un estudio sobre la producción del espacio geográfico.

Esta condición humana ha sido contrastada por diferentes autores como el filósofo alemán Friedrich Engels (1996) o el antropólogo estadounidense Marshall Sahlins (1974). Entre ellas, una de las aportaciones más sobresalientes se debe al geógrafo y noble ruso Piotr Alekseyevich Kropotkin, a través de su obra El apoyo mutuo. Su tesis principal descansa en la importancia de la ayuda mutua entre los miembros de una misma especie, e incluso entre individuos de especies distintas, como un factor notable de la evolución, especialmente de la evolución progresiva, pero no la única ni la que determina todo el proceso.

Kropotkin equipara, al menos en el mismo nivel de importancia, la ayuda mutua (socialización de especies) con la teoría de la "selección natural" de Charles Darwin, posteriormente llevada al extremo por Thomas H. Huxley, para acabar demostrando la transcendencia de la solidaridad y la ayuda mutua para la supervivencia y la evolución de las especies (Kropotkin, 1970). En su obra argumenta de una forma extensa que la simple confrontación y la guerra entre semejantes no es, de ningún modo, la ley primordial de la naturaleza y que, por el contrario, han existido numerosos ejemplos de sociabilidad ocurridos tanto en el mundo animal y vegetal como en la organización de los seres humanos en sociedad, a lo largo de toda la historia. De esta manera, P. Kropotkin afirma que «la ayuda mutua es el medio más justo para garantizar la seguridad máxima tanto para cada uno en particular como para todos en general. Es la mejor garantía para la existencia y el progreso físico, intelectual y moral. He aquí lo que nos enseña la naturaleza» (Kropotkin, 1970: 69).

Por tanto, la sociabilidad del ser humano y su capacidad para convivir y solidarizarse con otros miembros de la sociedad ofrece unas oportunidades formidables para la organización social del proceso de trabajo, así como para la producción del espacio, un elemento que no puede ser relegado al olvido. El ser humano es un ser eminentemente social y, por tanto, es preciso sobreponer esas cualidades a otras en la medida que ello suponga la construcción de un nuevo espacio geográfico. Sobreponerse implica, a su vez, cuestionarse las opciones de poder ejercidas por la sociedad en su transcurso histórico.

Entendidas como un hecho social, una oportunidad y también como una posibilidad, la cooperación y la ayuda mutua deben servir de táctica y de estrategia en la organización de la vida social y de la existencia humana. En consecuencia, la producción de un espacio cooperativo que aquí se propone rechaza la simple competencia como ley primordial entre los seres vivos, considerándolo "un estado excepcional" derivado de alteraciones puntuales en las condiciones de vida, por lo que la competitividad individual no constituye una regla

22 A la hora de referirse al concepto de "cooperación", Marx y Kropotkin lo aplican de forma diferente en sus análisis científicos. El primero, para definir las relaciones sociales y técnicas de trabajo dentro de la división del trabajo en el desarrollo del modo de producción capitalista; y el segundo, como factor social en la evolución de la humanidad. Empero, esta connotación no es óbice para concebir el valor ético de la cooperación como forma de sociabilidad. 
ni para el mundo animal, ni para el vegetal, ni para la humanidad (Kropotkin, 1970). De la misma forma, cabe resaltar el papel predominante que desempeña la acción colectiva (cooperativa) en el desarrollo de la vida y en la evolución de los seres humanos, en aspectos como la facilitación de la obtención y preparación de alimentos, la defensa mutua, favorecer la prolongación de la vida, asegurar la descendencia, mayor desarrollo de las facultades intelectuales, el disfrute de la vida en común, o bien para adaptarse a las exigencias de la naturaleza. Precisamente, la selección natural busca continuamente los medios colectivos a su alcance para evitar la competencia en cuanto sea posible, bien a través de la aplicación del apoyo mutuo entre individuos, o bien emigrando hacia otros lugares ${ }^{23}$. Una sociabilidad que el autor relaciona con "la necesidad experimentada por los animales de asociarse con sus semejantes, el amor a la sociedad por la sociedad, unido al goce de la vida" (Kropotkin, 1970: 55).

A este respecto, el geógrafo ruso añade un nuevo concepto llamado instinto de solidaridad humana o de sociabilidad, una "caución solidaria entre todos los hombres, y de sociabilidad" (Kropotkin, 1970: 15), que se ha venido desarrollando lentamente entre los animales y vegetales, y entre los seres humanos en el transcurso de su largo período de evolución. Por esta razón, señala que «la sociedad, en la humanidad, de ningún modo se ha creado sobre el amor ni tampoco sobre la simpatía (haciendo referencia a Büchner), se ha creado sobre la conciencia - aunque sea instintiva - de la solidaridad humana y de la dependencia reciproca de los hombres; [...] sobre el reconocimiento inconsciente o semiconsciente de las fuerzas que la práctica común de la ayuda mutua presta a cada hombre; sobre la dependencia estrecha de la felicidad de cada individuo de la felicidad de todos, y sobre los sentimientos de justicia o equidad, que obligan al individuo a considerar los derechos de cada uno de los otros como iguales a sus propios derechos» (Kropotkin, 1970: 15).

Así, la solidaridad, queda entendida como una solidaridad internacionalista de clase, contextualizada dialécticamente en un espacio dominado por el dogma de la competitividad más ardua y del individualismo extremo. Las interrelaciones solidarias asentadas en la práctica de una ayuda mutua entre seres humanos representan un factor histórico en las luchas conquistadas por una clase empobrecida, a escala internacional. Se trata de reivindicar de una forma consciente la fuerza que se adquiere practicando el apoyo mutuo, la cooperación o la solidaridad, revalorizando este factor clave en la producción y transformación del espacio geográfico.

Con la argumentación de Kropotkin se confirma que la cooperación y solidaridad no se desarrollan individualmente sino que se trata siempre de una "variación de grupo". Ello representa un avance cuantitativo, pero, sobre todo, un paso de tipo cualitativo en relación a la propuesta de territorializar un trabajo cooperativo. Se constata de esta manera la oportunidad que representa la ayuda mutua colectiva, propia de pueblos y comunidades históricas (entre ellas, las campesinas), como elemento de resistencia frente a los embates de la lógica del capital, pero que al mismo tiempo se proyecta como parte de una estrategia revolucionaria para la transformación socioespacial a través de esta praxis, es decir, de la materialización real de un trabajo (inter)cooperativo en los diversos territorios.

23 De esta manera, Kropotkin contradice las teorías de Malthus sobre la competencia por los alimentos y el futuro estado de superpoblación de las especies. Argumenta, además, que existen diversas causas y ejemplos que nunca permitirán llegar a tal límite. 
Ante esta argumentación, se han observado diferencias en las cooperativas (agrarias), las cuales, algunas de ellas, reproducen la cooperación como práctica competitiva y de supervivencia intercapitalista. Esta deriva refleja una profunda complejización del contrariado sentido de la cooperación y la ayuda mutua en el seno del movimiento cooperativo, dilucidada en esta investigación.

En definitiva, la producción de un espacio cooperativo ofrece la posibilidad de transmitir una nueva organización territorial y espacial de la vida social, atendiendo a esta posibilidad de transformación del espacio geográfico, mediante la generalización de la práctica de valores tales como la ayuda mutua, la cooperación y la solidaridad en la dependencia recíproca entre los seres humanos. Valores que ejercen, consiguientemente, una influencia activa en la dialéctica del espacio.

\section{ESPACIO Y TERRITORIO(S): TERRITORIALIDADES EN EL ESPACIO GEOGRÁFICO}

Asimismo, cabe analizar la conceptualización del territorio ligada a la producción del espacio planteado en el presente artículo. Por su parte, el territorio (o territorios) constituye un elemento indisociable de la producción del espacio y es considerado, por ende, como un subespacio. El territorio, como subespacio, no es ajeno a las interrelaciones dialécticas que predominan en la producción del espacio geográfico como un todo. No obstante, el territorio y los territorios presentan dinámicas propias, asimétricas y diferenciadas, pero que responden a una misma lógica de producción espacial mayor. En este sentido el espacio y el territorio interactúan dialécticamente identificándose las partes con el todo. No obstante, «grandes equívocos se deben a la confusión conceptual en relación al espacio y el territorio» (Haesbaert, 2007: 44).

El territorio cristaliza unas determinadas relaciones entre la sociedad y la naturaleza, es decir, representa la materialización específica y singular del espacio geográfico. En consecuencia, desde una perspectiva dialéctica, espacio y territorio son términos que están estrechamente unidos pero no son sinónimos. En relación al espacio, el geógrafo suizo Claude Raffestin apunta que este se encuentra en una situación anterior al territorio, por lo que el territorio se forma a partir del espacio, como resultado de una acción conducida por un actor sintagmático (syntagmatique), es decir, aquel que realiza un programa; y en esa apropiación de un espacio, de forma concreta o abstracta, el actor "territorializa" el espacio (Raffestin, 1993: 143). De modo que la producción del espacio se encuentra en un continuo proceso de construcción de territorios o territorialidades a diferentes escalas geográficas, envolviendo siempre una interrelación entre la naturaleza y la sociedad. Así, el territorio se presenta como una producción social a partir del espacio, como un subespacio inscrito dentro de unas definidas relaciones de poder.

El concepto de "territorio" ha sido abordado por innumerables autores, tanto desde la Geografía como por parte de las demás ciencias sociales ${ }^{24}$. Empero, el debate sobre el territorio ha recuperado un mayor protagonismo si cabe a partir de los trabajos sobre la "territorialidad" (Raffestin, 1993) y los procesos de "territorialización” y "desterritorialización"

24 Gran número de ellas están vinculadas a la contemporánea concepción de "desarrollo territorial”, "organización del territorio" o "desarrollo local". 
(Haesbaert, 2007; Saquet, 2010), realizados desde un análisis eminentemente geográfico y vinculándolos a la causalidad dialéctica del espacio como parte de la realidad social en proceso de totalización.

Es en esta dinámica espacial, integrada en la realidad social total, donde quedan insertas una compleja dinámica de "territorialidades", entendidas como procesos diferenciadores del territorio que coexisten en un mismo movimiento unitario del proceso de producción espacial. Para Marco Saquet «el espacio y el territorio son vistos como ligados e indisociables. El proceso de territorialización es un movimiento históricamente determinado; es uno de los productos socioespaciales del movimiento y de las contradicciones sociales bajo las fuerzas económicas, políticas y culturales, que determina las diferentes territorialidades, en el tiempo y en el espacio, las propias desterritorialidades y las reterritorialidades [...]. El territorio es producto y condición de la territorialización. Los territorios son producidos espacio-temporalmente por el ejercicio del poder por determinado grupo o clase social, o sea, por las territorialidades cotidianas. Las territorialidades son, simultáneamente, resultado, condicionantes, y caracterizadoras de la territorialización y del territorio» (Saquet, 2010: 127).

Saquet expresa la territorialidad en términos de relaciones diarias, un acontecer de todas las actividades cotidianas y formas de vida, como las relaciones con la casa, el trabajo, la familia, la escuela, el ocio y la diversión, la práctica de una religión, etcétera.; se trata, no obstante, de un proceso constructivo de gran complejidad social y de relaciones de dominación entre individuos y grupos sociales que se desarrollan en una parcela del espacio geográfico. No se trata aquí de comprender simplemente de una forma aislada los procesos territoriales y los territorios sino de explicar sus relaciones causales de existencia, su dinamismo y su forma de materialización en la realidad (social) espacial actual para transformarla. De modo que, como propone el geógrafo italiano Giuseppe Dematteis, la territorialidad quede definida como "una construcción social” (Saquet, 2010), viabilizando así la oportunidad de territorializar la cooperación y la ayuda mutua como factores sociales relevantes en la producción del espacio.

Atendiendo a esta noción de construcción social del territorio, es preciso profundizar en aquello que se territorializa y aquello otro que se desterritorializa, para avanzar seguidamente en lo que se pretende reconstruir o reterritorializar.

\section{III.1. Dinámicas de territorialización, desterritorialización y reterritorrialización}

En el espacio del capital, lo que se territorializa es su propia lógica de reproducción, con el objetivo de facilitar la circulación del capital y la creación de oportunidades de acumulación. Aunque, de la misma manera, se territorializan sus crisis estructurales, considerando sendos procesos como partes de un mismo movimiento dialéctico. La territorialización de unas dinámicas, de aquellas personas, colectivos, o clase social, que poseen la propiedad del capital y se benefician de su vocación de acumulación, implica potencialmente la desterritorialización de otras.

La territorialización y desterritorialización se encuentran entrelazadas a partir de las numerosas referencias que permiten la configuración de un espacio por y para la lógica del capital y su expansión territorial. Sus improntas derivan de: la dinamización de flujos 
financieros, comerciales y de circulación del capital sin necesidad de una materialización física; el progreso de la técnica, los avances de la alta tecnológica, la informática y la robótica; la consolidación del trabajo virtual y del trabajo en red; la revolución de las telecomunicaciones, la expansión de Internet y las redes sociales virtuales; el aumento de la dimensión de las empresas (transnacionalización), la complejidad del proceso productivo y la diversidad de factores de localización; la división social y territorial de la producción; la generalización de los grandes centros de consumo; de la consolidación de grandes concentraciones urbanas (macrocefalias urbanas), entre otros muchos ejemplos de la era de la Globalización.

En consecuencia dialéctica, la desterritorialización con respecto al espacio del capital podría estar representada por otra serie de huellas territoriales: la liberalización económica y la privatización de servicios sociales públicos; la despolitización y minimización de las responsabilidades de los Estados-nación; la deslocalización y flexibilización del trabajo productivo; la configuración de redes de ciudades con nuevos nodos y puntos (locus) estratégicos para la acumulación de capital (bolsas de Tokio, Londres, París o Nueva York); lugares que cambian su significado en relación a la coyuntura de un mundo globalizado; la toma de decisiones político-económicas en instancias alejadas con efectos sociales a diferentes escalas; la expulsión de comunidades campesinas e indígenas, los conflictos sociales y las migraciones forzadas, entre otras realidades existentes también en la era de la Globalización.

Así, el término "desterritorialización” hace referencia a la obligación de una movilidad internacional de personas y al propio éxodo rural, en este caso, de aquellas migraciones motivadas directamente por los impactos del interés capitalista en diferentes territorios (como guerras, conflictos, contaminación, hambre, empobrecimiento, etcétera). El capital territorializa sus propias contradicciones de acumulación de capital y de empobrecimiento, adquiriendo una dinámica que desterritorializa a la sociedad de su propia naturaleza, convirtiendo al ser humano en un simple homo economicus, una concepción que no es compartida por todos los "sujetos sociales" que componen la realidad social.

Por tanto, como indica el profesor Haesbaert, el proceso de desterritorialización en la época contemporánea obedece a un proceso de exclusión social, o mejor, de exclusión socioespacial (Haesbaert, 2007: 68) dentro de un contexto histórico globalizado, donde existen elementos básicos de territorialización y desterritorialización. De la misma forma, distingue entre una desterritorialización de "los de arriba" y otra de "los de abajo"25, es decir, un proceso inserto en un conflicto social, en una lucha de clases. Y con ello analiza este proceso de una forma material e identitaria, conjugando las relaciones político-económicas y la dimensión simbólica-cultural.

Desde la perspectiva de producción del espacio cooperativo, se conserva la visión de una desterritorialización de "los de abajo", que hace referencia a aquella provocada directa o indirectamente por la territorialidad predominante del capital y de su lógica de reproducción.

25 Con desterritorialización de "los de arriba" se refiere a la parte de la sociedad más privilegiada, usuarios de la cibertecnología, la informática y el mundo "virtual" (inmaterial). Véase conceptos como "Cibercultura" o "Virtualidad". En cambio, la desterritorialización de "los de abajo" es para referirse a una privación de acceso a la tierra como base principal de la reproducción social, es decir, una desterritorialización en ocasiones literal (Haesbert, 2007: 62). 
En consecuencia, la reterritorialización se entiende aquí como aquella propuesta de transformación socioeconómica, política y cultural (identitaria) y, por supuesto, espacial, a partir de las propuestas desplegadas por los movimientos sociales del campo y la reorganización espacial del trabajo cooperativo.

El significado de "reterritorialización" en el contexto histórico actual enfrenta la territorialización dominante de las contradicciones del capital. Es en este contexto que, por ejemplo, los movimientos sociales del campo tratan de (re)territorializar su trabajo campesino y colectivo, sus formas de vida y su acción social, proyectando sobre el territorio la producción de un nuevo espacio, nuevas relaciones de poder y de atención a la identidad cultural.

En relación al objeto que compete a este artículo, la reterritorialización significa principalmente la materialización de una práctica de la ayuda mutua y de la solidaridad ${ }^{26}$ en las relaciones sociales de trabajo y de producción; o sea, la organización de un trabajo cooperativo y la creación de estructuras cooperativas y de intercooperación cooperativa que articulen la dinámica socioeconómica y política de una sociedad; y con ello la proyección de su esencia en el espacio geográfico. Esta interpretación de la reterritorialización vendría a expresar la territorialización del valor del trabajo frente a la del capital, la reapropiación colectiva de los medios de producción, una restauración de las relaciones sociales de producción y la socialización del producto del proceso del trabajo. Asimismo, se propone una priorización de lo público, de lo colectivo, la socialización del conocimiento y la información, la internacionalización de un acceso real a la alimentación y al agua potable, a la educación, la salud, la vivienda, la movilidad y el transporte, y la energía, entre otras garantías básicas para la vida en sociedad.

La reterritorialización apuntaría hacia la recuperación del territorio como identidad social y colectiva a favor de la conservación de todas las formas de vida integradas en ecosistemas, agroecosistemas o etnoagroecosistemas ${ }^{27}$. Por sus características específicas, queda aquí implicada la forma de vida campesina y otras formas de vida no-capitalistas que coexisten en la actualidad (indígena), y que aún hoy se anteponen a la artificialidad del modo de producción capitalista y contra el alejamiento progresivo del ser humano de su propia naturaleza, en el sentido más profundo del término.

En consecuencia, se impulsa una alternativa social y espacial -como proyecto socioespacial- promovida fundamentalmente por movimientos sociales, movimientos socioterritoriales o socioespaciales (Fernandes, 2005), los cuales pretenden recuperar la función del ser humano como integrante activo de la naturaleza en su relación dialéctica. Una reterritorialización que surge a partir de un cuestionamiento de las relaciones de poder dominantes y de las causas de la pérdida de identidad territorial en el espacio geográfico producido por y para el capital. Es decir, por la territorialización de una praxis cooperativa en diferentes esferas del modo de producción con el objetivo de transformar el espacio del capital y sus territorios de empobrecimiento.

26 Entendida aquí como una solidaridad internacionalista de clase o "solidaridad revolucionaria". No una solidaridad filantrópica, asistencialista o caritativa.

27 Términos desarrollados por la ciencia ecológica, la agroecología y la ecología política; concretamente en Sevilla Guzmán (2006) y Altieri (2012). 


\section{CONCLUSIONES}

A partir de un análisis dialéctico del proceso de totalización de la realidad y del espacio como parte de esa totalidad social, la transformación del espacio se muestra como una realidad en potencia. Un nuevo paradigma de organización social requiere la producción de un nuevo espacio geográfico posible, donde se desarrollen otras formas de trabajo y otras formas de vida.

El espacio queda entendido como un producto histórico y social, ligado a los procesos de producción, la organización del trabajo y los avances de la técnica. Así, el modo de producción, en su acepción más amplia, y la organización del proceso de trabajo adquieren una categoría de especial interés en el análisis espacial. No obstante, el capital, entendido como proceso, modela y racionaliza el espacio a partir de su lógica de acumulación y su carácter geográficamente expansivo. Por ello, la ayuda mutua y el trabajo cooperativo son considerados nuevos elementos de territorialización que ostenta la posibilidad de alterar potencialmente la racionalidad espacial del modo de producción capitalista.

Finalmente, el territorio (los territorios), entendido como un subespacio, presenta dinámicas contradictorias dentro de la misma producción espacial del capital, una deriva que se manifiesta mediante los procesos de territorialización, desterritoriarilización y reterritorialización. Bajo esta dinámica son los movimientos sociales del campo, movimientos socioterritoriales o socioespaciales, entre otros, aquellos que protagonizan una reterritorialización fundamentada en el reaprendizaje de una práctica cooperativa, en la organización del trabajo cooperativo como eje central de la vida social y como acción de transformación espacial en aras de la producción de un nuevo espacio geográfico, un espacio cooperativo.

\section{BIBLIOGRAFÍA}

ALTIERI, M.A. (2012): Agroecología: bases científicas para uma agricultura sustentável. $3^{\mathrm{a}}$ ed. São Paulo, Rio de Janeiro: Expressão Popular, AS-PTA, 400 p.

CARLOS, A.F.A. (2007): “O consumo do espaço". En: Carlos, Ana Fani A. (Org.): Novos caminhos da geografia. São Paulo: Contexto, 173-186 p.

DURKHEIM, É. (1967): De la division du travail social. Paris: Presses Universitaires de France, $416 \mathrm{p}$.

ENGELS, F. (1996): El origen de la familia, la propiedad privada y el Estado. 13ªdición. Madrid: Fundamentos, 223 p.

FERNANDES, B.M. (2005): "Movimentos socioterritoriais e movimentos socioespaciais". Observatorio Social de América Latina., v. 16, Buenos Aires: CLACSO, pp. 273-284.

FOUCAULT, M. (2006): Seguridad, territorio, población: Curso en el Collège de France 1977-1978. $1^{\text {a }}$ ed. Buenos Aires: Fondo de Cultura Económica, 488 p.

GOMES, H. (1991): A produção do espaço geográfico no capitalismo. São Paulo: Contexto, $2^{\mathrm{a}}$ edição, 74 p.

HARVEY, D. (1990): Los límites del capitalismo y la teoría marxista. México D. F.: Fondo de Cultura Económica, 469 p.

HARVEY, D. (2007a): Espacios del capital: hacia una geografía crítica. Madrid: Akal, $445 \mathrm{p}$. 
HARVEY, D. (2007b): Breve historia del neoliberalismo. Madrid: Akal, 252 p.

HAESBAERT, R. (2007): "Concepões de território para entender a desterritorialização". En: VV AA: Território, territórios. Ensaios sobre o ordenamento territorial. $3^{\text {a }}$ edição. Rio de Janeiro: Lamparina, pp. 43-72.

HARNECKER, M. (2007): Los conceptos elementales del materialismo histórico. Madrid: Siglo XXI, 296 p. [1969].

KROPOTKIN, Piotr A. (1970): El apoyo mutuo: un factor de la evolución. Madrid: Zero, 243 p. [1902].

KROPOTKIN, P.A. (1978): Campos, fábricas y talleres. Madrid: Júcar, 172 p. [1898].

KROPOTKIN, P.A. (1994): "Lo que la Geografía debe ser”. En: Gómez Mendoza, Josefina; Muñoz Jiménez, Julio; Ortega Cantero, Nicolás: El pensamiento geográfico: Estudio interpretativo y antología de textos (de Humboldt a las tendencias radicales). $2^{\mathrm{a}}$ ed. Madrid: Alianza Universidad Textos, pp. 227-240[1885].

LEFEBVRE, H. (2000a): Espace et politique. Le droit à la ville II. $2^{\mathrm{a}}$ ed. Paris: Antrophos, $174 \mathrm{p}$.

LEFEBVRE, H. (2000b): La production de l'espace. 4ª ed. Paris: Antrophos, 489 p. [1976].

LEFEBVRE, H. (2002); La survie du capitalisme. La reproduction des rapports de production. $3^{\mathrm{a}}$ ed. Paris: Antrophos, 225 p.

LENIN, Vladimir I. (1974): El imperialismo, fase superior del capitalismo. Madrid: Fundamentos, 148 p. [1916].

LENIN, V.I. (1976): El Estado y la revolución. Madrid: Ayuso, 156 p. [1917].

LIPIETZ, A. (1979): El capital y su espacio. México: Siglo XXI, 203 p.

LUXEMBURG, R. (2009): Reforma o Revolución. Madrid: Diario Público, 111 p. [1899].

MARX, K. (1975a): "Salario, precio y ganancia". En: Marx, K. y Engels, F.: Obras Escogidas. Madrid: Akal. Vol.1, 410-465 p.

MARX, K. (1975b): “Trabajo asalariado y capital”. En: Marx, K. y Engels, F.: Obras Escogidas. Madrid: Akal. Vol.1, 71-99 p.

MARX, K. (2010a): El Capital: El proceso de producción del capital. Libro primero, tomo I. Madrid: Siglo XXI, 381 p.

MARX, K. (2010b): Las crisis del capitalismo. Madrid: Diario Público, 115 pp.

MORAES, A.C.R.; MESSIAS, W. da Costa (1985): A valorização do espaço. São Paulo: Hucitec, 196 p.

MOREIRA, R. (1993): O que é geografia. $2^{\mathrm{a}}$ ed. São Paulo: Brasiliense, 95 p.

POLITZER, G. (2002): Principios fundamentales y elementales de Filosofía 1932-1935. Universidad Obrera de París. $2^{\mathrm{a}}$ ed. Madrid: Alba, 272 p.

RAFFESTIN, C. (1993): Por uma Geografia do poder. São Paulo: Ática, 269 p.

SAHLINS, M. (2010): Economía de la edad de piedra. Barcelona: Akal, 337 p. [1974]

SÁNCHEZ, J.E.(1981): La geografia y el espacio social del poder. Barcelona: Libros de la frontera, $248 \mathrm{p}$.

SANTOS, M. (2008a): Espaço e método. São Paulo: Edusp, 122 p. [1985].

SANTOS, M. (2008b): Por uma geografia nova. 6a ed. São Paulo: Edusp, 288 p. [1978].

SANTOS, M. (2008c): Técnica, espaço, tempo. São Paulo: Edusp, 176 p. [1994].

SANTOS, M. (2009a): A natureza do espaço: técnica e tempo, razão e emoção. $4^{\mathrm{a}}$ ed. São Paulo: Edusp, 388 p. [1996]. 
SANTOS, M. (2009b): Pensando o espaço do homem. $5^{\text {a }}$ ed. São Paulo: Edusp, 96 p. [1982]. SAQUET, M.A. (2010): Abordagens e concepções de territorio. São Paulo: Expressão Popular, $200 \mathrm{p}$.

SARTRE, J.P. (2005): Questions de méthode. Paris: Gallimard, 168 p. [1957].

SEVILLA GUZMÁN, E. y GONZÁLEZ DE MOLINA, M. (2005): Sobre a evolução do conceito de campesinato. São Paulo: Expressão Popular, 96 p.

WALLERSTEIN, I. (1988): El capitalismo histórico. Madrid: Siglo XXI, 103 p. 